University of Nebraska - Lincoln

DigitalCommons@University of Nebraska - Lincoln

Biological Systems Engineering: Papers and

Publications

Biological Systems Engineering

2015

Control System Development And Response Analysis Of An Electronically Actuated Variable-Orifice Nozzle For Agricultural Pesticide Applications

Joe D. Luck

University of Nebraska-Lincoln, jluck2@unl.edu

S. A. Shearer

Ohio State University

M. P. Sama

University of Kentucky, michael.sama@uky.edu

Santosh Pitla

University of Nebraska-Lincoln, spitla2@unl.edu

Follow this and additional works at: https://digitalcommons.unl.edu/biosysengfacpub

Part of the Bioresource and Agricultural Engineering Commons, Environmental Engineering Commons, and the Other Civil and Environmental Engineering Commons

Luck, Joe D.; Shearer, S. A.; Sama, M. P.; and Pitla, Santosh, "Control System Development And Response Analysis Of An Electronically Actuated Variable-Orifice Nozzle For Agricultural Pesticide Applications" (2015). Biological Systems Engineering: Papers and Publications. 466.

https://digitalcommons.unl.edu/biosysengfacpub/466

This Article is brought to you for free and open access by the Biological Systems Engineering at DigitalCommons@University of Nebraska - Lincoln. It has been accepted for inclusion in Biological Systems Engineering: Papers and Publications by an authorized administrator of DigitalCommons@University of Nebraska Lincoln. 


\title{
CONTROL SYSTEM DEVELOPMENT AND RESPONSE ANALYSIS OF AN ELECTRONICALLY ACTUATED VARIABLE-ORIFICE NOZZLE FOR AGRICULTURAL PESTICIDE APPLICATIONS
}

\author{
J. D. Luck, S. A. Shearer, M. P. Sama, S. K. Pitla
}

\begin{abstract}
The goal of this research project was to further the development of an electromechanically controlled variable-orifice nozzle by creating an electronic control system and then evaluating that system based on step and ramp inputs. The control system was developed in a programming environment that combined an electronic data acquisition system and actuator with pressure and flow sensors. A proportional, variable-gain (based on system pressure) control system was developed to adjust nozzle flow rates to meet target application rates. The constraints were to achieve settling time of less than $1.0 \mathrm{~s}$, overshoot of less than 10\% of maximum flow (or minimum flow), and average absolute steady-state error of less than $2 \%$. After several trials, the resulting control system achieved these objectives for full steps from maximum and minimum flow rates (and vice versa) at carrier pressures from 140 to $410 \mathrm{kPa}$. Ramp response analyses revealed the maximum flow rate change $\left(\mathrm{mL} \mathrm{s}^{-2}\right)$ of the nozzle control system. Operation was considered successful if the average absolute error was less than $5 \%$ and the average absolute error $+2 \sigma$ did not exceed $10 \%$ of the desired flow, thereby ensuring that the nozzle operated within specifications $95 \%$ of the time. An additional goal was to maintain nozzle response lag times of less than $1.0 \mathrm{~s}$ based on input rate changes in the form of ramp signal input frequencies. Lag times were found to be less than $0.5 s( \pm 0.05 \mathrm{~s})$ over the carrier pressure range at input frequencies of up to $0.2 \mathrm{~Hz}$. Further, these results indicated that for each carrier pressure, a maximum rate change frequency of $0.07 \mathrm{~Hz}$ ensured that system errors were within the design requirements. Lag times at this frequency were less than $0.38 \mathrm{~s}$ for all carrier pressures tested. The range of rate change achieved by the nozzle control system ranged from 2.97 to $6.39 \mathrm{~mL} \mathrm{~s} \mathrm{~s}^{-2}$ for carrier pressures of 140 to $414 \mathrm{kPa}$, respectively. Thus, as operating pressure increased, the nozzle was capable of compensating for greater changes in the desired flow rate. While the turndown ratios ( 2.4:1) over the range of carrier pressures were essentially stable, flow rates increased with carrier pressure.
\end{abstract}

Keywords. Pesticide efficacy, Precision agriculture, Spraying equipment, Variable-rate application.

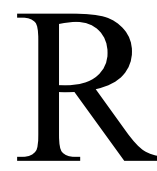
esearch and development of advanced technologies for application systems continues at a rapid pace. Systems for controlling liquid application systems (e.g., for pesticides or fertilizer) have recently been focused on as manufacturers seek to improve application accuracy while reducing the effects of spray drift moving products off-target. Pulse-width modulation

Submitted for review in September 2014 as manuscript number MS 10945; approved for publication by the Machinery Systems Community of ASABE in June 2015.

The information reported in this article (No. 15-05-032) is part of a project of the Kentucky Agricultural Experiment Station and is published with the approval of the Director. Mention of trade names is for informational purposes only and does not necessarily imply endorsement by the Kentucky Agricultural Experiment Station.

The authors are Joe D. Luck, ASABE Member, Assistant Professor, Department of Biological Systems Engineering, University of NebraskaLincoln, Lincoln, Nebraska; Scott A. Shearer, ASABE Member, Professor and Chair, Department of Food, Agricultural and Biological Engineering, The Ohio State University, Columbus, Ohio; Michael P. Sama, ASABE Member, Assistant Professor, Department of Biosystems and Agricultural Engineering, University of Kentucky, Lexington, Kentucky; Santosh K. Pitla, ASABE Member, Assistant Professor, Department of Biological Systems Engineering, University of NebraskaLincoln, Lincoln, Nebraska. Corresponding author: Joe Luck, 206 L.W. Chase Hall, University of Nebraska-Lincoln, Lincoln, NE 68583-0726; phone: 402-472-1488; e-mail: jluck2@unl.edu.
(PWM) is one such technology that has been studied as a potential option for variable-rate application. To vary chemical application rates using PWM, electric solenoid valves are placed upstream of boom section valves or nozzles. The solenoid valves are then pulsed on and off at a desired frequency. The input signal to the solenoid valve is typically a square wave with a duty cycle from $0 \%$ to $100 \%$, the latter representing the valve in the fully open position. Flow through the nozzle can be varied by adjusting the duty cycle and/or the operating frequency of the solenoid valve. Development and assessment of the viability of such nozzle control systems has received some attention in recent decades (Giles and Comino, 1990). Giles et al. (1995) studied the effects on droplet sizes from fan nozzles that used PWM control.

Further study into the effects of PWM control on hydraulic atomizers indicated that a 10:1 flow rate reduction was possible at fixed carrier pressures (Giles, 1997). GopalaPillai et al. (1999) evaluated PWM flow control on a nozzle for site-specific application and found that the droplet spectra were fairly consistent for duty cycles from $50 \%$ to $100 \%$; however, droplet sizes were significantly different for duty cycles around $10 \%$. Study results concluded that the spray pattern was preserved within acceptable limits 
with changes in the nozzle control valve duty cycle.

Han et al. (2001) modified a commercial sprayer using PWM solenoid control to affect variable-rate control of the spray material. Results indicated that the flow rate response of the valves to the PWM signals created noticeable volumetric errors. Flow rate control errors for the valves ranged from $-15 \%$ to $12 \%$ when using a single flow rate calibration curve. Pierce and Ayers (2001) studied the effects of PWM control on spray deposition and application accuracy. The system flow rates responded well to control with PWM (4\% error from theoretical), while the CV of the spray pattern in the direction of travel ranged from $10 \%$ to $65 \%$. Efficacy variation was less noticeable after pre-emergence treatments; however, weed control varied from $65 \%$ to $100 \%$ during post-emergence treatments.

More recently, Lebeau et al. (2004) proposed the development of a controller to compensate for the effects of horizontal boom movements with the use of individual PWM single-nozzle control in mind. Results indicated that the idea was feasible based on tests conducted with one nozzle using PWM flow control when these results were extrapolated across the boom width. Similarly, Shahemabadi and Moayed (2008) proposed a system for controlling individual spray nozzles using PWM for solenoid valves added to a commercial sprayer. Results indicated that the pressure controller was not capable of maintaining adequate pressure across the boom due to fluctuations induced by PWM of the valves. The study concluded that additional control of the manifold for total boom flow rate could improve the performance of the proposed system. To date, only two commercially available system are being marketed that use PWM to affect variable-rate pesticide application. The PinPoint and SharpShooter systems available from Capstan $\mathrm{Ag}$ Systems, Inc., use PWM solenoids to act as pre-orifices to control discharge from the nozzles (Capstan, 2011). A second system has recently become available: the Hawkeye system from Raven Industries. A recent study by Porter et al. (2013) indicated that this control system could maintain errors within $\pm 10 \%$ for the various turning scenarios tested.

Variable flow rate options for nozzle discharge using PWM solenoid valves have been discussed above. Other methods for varying nozzle flow rate studied in the past include bypass spray nozzle valves (Han et al., 1986), swirl nozzles with varying inlet openings (Koo and Kuhlman, 1993), and pinch valves ahead of the nozzle (Kunavut et al., 2000). Within the last few years, a new concept for variable-rate technology has emerged in the form of a variable orifice design. This technology achieves variable-rate application by modifying the size and shape of the orifice. The development of this technology began in the late 1990s by Bui (1997), who tested a variable-orifice nozzle and found that flow rates and droplet spectra could both be varied. Womac (2001) evaluated the atomization characteristics of variable-orifice flood nozzles. These nozzles required external adjustment to change the orifice diameter, which would not be feasible with current technology for on-the-go modification during field application.

Design and testing of a variable-flow fan nozzle was conducted by Womac and Bui (2002). This design used a split-end metering plunger controlled by spring force in a tapered sleeve above the nozzle orifice cavity. As liquid pressure in the nozzle increased, the diaphragm applied force to the spring, which increased the orifice size by moving the plunger farther out of the sleeve. As liquid pressure decreased, the spring forced the plunger farther into the sleeve, thereby decreasing the orifice size. Test results indicated that turndown ratios on the order of 13:1 were possible with this new design. Overall, the reaction of the system (spring force to liquid pressure) made it possible to control the liquid flow rate through the nozzle as well as the droplet size spectra.

A similar system was developed and tested by Bui (2005) that used spring force to move a metering plunger in and out of an orifice. In addition to the system previously discussed (Womac and Bui, 2002), the VariTarget (VT) nozzle included a method of adjusting the shape of the nozzle orifice as the metering plunger moved in and out of the sleeve (Bui, 2005). Testing of this nozzle indicated that as liquid pressure varied from 104 to $345 \mathrm{kPa}$, VT nozzle flow rates ranged from 0.57 to $3 \mathrm{~L} \mathrm{~min}{ }^{-1}$. The spray angle and distribution of material were found to be consistent over the flow rate ranges, while the response time of the spring force to changes in liquid pressure was less than $0.25 \mathrm{~s}$. While the system developed by Bui (2005) advanced the capacity of droplet size control with variable-orifice nozzles, the system was still reactive in nature, as the spring force on the metering plunger reacted to changes in pressure to control the flow rate, spray deposition pattern, and droplet size distribution.

Daggupati (2007) conducted a study of the various VT nozzles (differing caps for fine, medium, coarse, or very coarse droplet sizes) and determined that the nozzles had turndown ratios of up to 12:1. Spray pattern angle testing indicated that pressures below $207 \mathrm{kPa}$ may lead to a reduction in the spray angle $\left(110^{\circ}\right.$ target). Further tests on the VT nozzle indicated that flow rates could be maintained with a CV of less than $10 \%$ across the spray boom, with the optimal performance occurring at a carrier pressure of $276 \mathrm{kPa}$ and above (Dilawari et al., 2008). These studies suggest that it might be possible to achieve variable-rate application by changing system pressure (or flow rate) using the original VT nozzle configuration. However, as previously discussed, controlling system pressure can be difficult as spray rate controllers attempt to compensate for ground speed changes or boom section actuation.

To create an active control method for the VT nozzle, Luck et al. (2010) modified the existing VT nozzle (green cap) by essentially replacing the spring force with air pressure, which was varied using an electro-pneumatic valve. Tests were conducted using constant liquid carrier pressure (70 to $280 \mathrm{kPa}$ ) while the air pressure on the diaphragm was varied to adjust the position of the metering plunger. Results indicated that flow rates ranged from $0.8 \mathrm{~L} \mathrm{~min}^{-1}$ (70 kPa carrier pressure at maximum air pressure) to $6.8 \mathrm{~L}$ $\min ^{-1}$ (276 $\mathrm{kPa}$ carrier pressure at minimum air pressure). These tests demonstrated that by maintaining the carrier pressure while varying the orifice size and shape, it was possible to achieve a wide variation of flow rates from such a nozzle configuration.

While several advances in application control technolo- 
gies have been made in recent years, room for additional growth and the need for emerging technologies are evident. The overall goal of this research was to develop and evaluate the response characteristics of a new pesticide application delivery system consisting of an actively actuated (direct-operated electromechanical) variable-orifice nozzle for controlling carrier flow rate using a constant-pressure system. Specific objectives were to (1) create an electronic control system for managing nozzle flow rates based on step and ramp input commands and (2) evaluate the ability of the control system to successfully respond to those inputs based on acceptable errors demonstrated from previous researchers (e.g., maximum error and lag times).

\section{MATERIALS AND MeTHODS}

\section{NOZZLE MODIFICATION AND INSTRUMENTATION}

The VT variable-orifice nozzle (VariTarget, Delavan AgSpray Products, Mendota Heights, Minn.) with green cap (for very coarse droplets) was selected for use in this study. According to manufacturer data, the VT nozzle with green cap can be used to deliver application rates of around $95 \mathrm{~L} \mathrm{ha}^{-1}$ (very coarse droplets) at typical pressures and velocities used for many self-propelled sprayers (Delavan, 2011). The spring housing assembly was removed from the original VT nozzle and replaced with an assembly machined to attach the metering stem and diaphragm to an electric linear actuator. To accomplish this, the metering stem was drilled and tapped so that the diaphragm could be tightly sealed on top of the metering stem. The metering stem was forced downward to decrease orifice size and reduce the nozzle flow rate, which was similar in operation to the original VT nozzle. As the metering stem was retracted (upward), the orifice size increased to allow higher nozzle discharge rates. The VT nozzle was attached to a single nozzle body (22251-311-750-NYB, TeeJet Technologies, Wheaton, Ill.) with $19 \mathrm{~mm}$ i.d. hose connecting the system components. The components necessary for adapting the VT nozzle for electronic actuation are shown in figure 1. Detailed CAD drawings of the modified components can be found in Luck (2012).

Carrier was supplied by a smooth-flow helical rotor pump (101B, Oberdorfer Pumps, Syracuse, N.Y.) driven by a $0.56 \mathrm{~kW} 115 \mathrm{VAC}$ motor operating at $1725 \mathrm{rpm}$. Carrier pressure was controlled with a pressure regulating (PR) valve (model 23120, TeeJet Technologies, Wheaton, Ill.). Carrier pressure was constantly monitored using a calibrated pressure transducer (PX309-100G5V, Omegadyne, Inc., Sunbury, Ohio) that was powered via a 12 VDC input and provided a 0 to $5 \mathrm{VDC}$ output signal proportional to the system pressure. System flow rate was monitored using an electromagnetic flowmeter with a digital display (FMG202NPT, Omega Engineering, Inc., Stamford, Conn.). An 80mesh inline filter (39908-1, Delavan AgSpray Products, Mendota Heights, Minn.) was placed in the circuit between the reservoir and pump. A diagram of the system is shown in figure 2.

A linear actuator (NA14B16, Zaber Technologies, Inc., Vancouver, B.C., Canada) was selected to control the metering stem position for the modified VT nozzle. Actuator displacement and force (Zaber, 2015) required were esti-

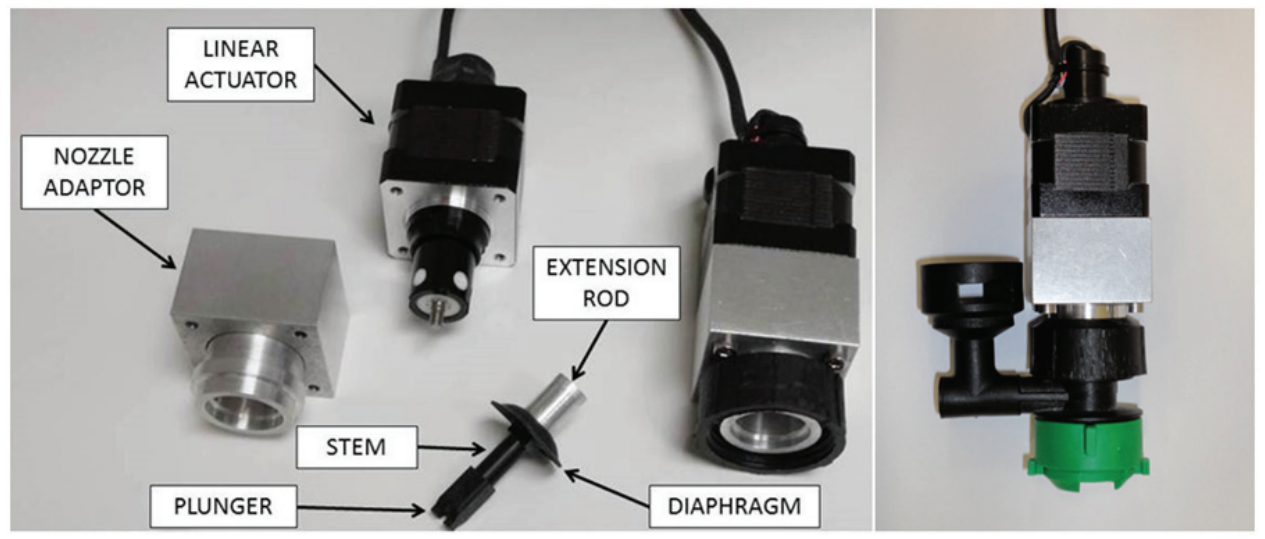

Figure 1. Components (left) of adapted VT nozzle used for testing; the extension rod is threaded into the full assembly and then attached to the original VT nozzle housing for actuation (right).

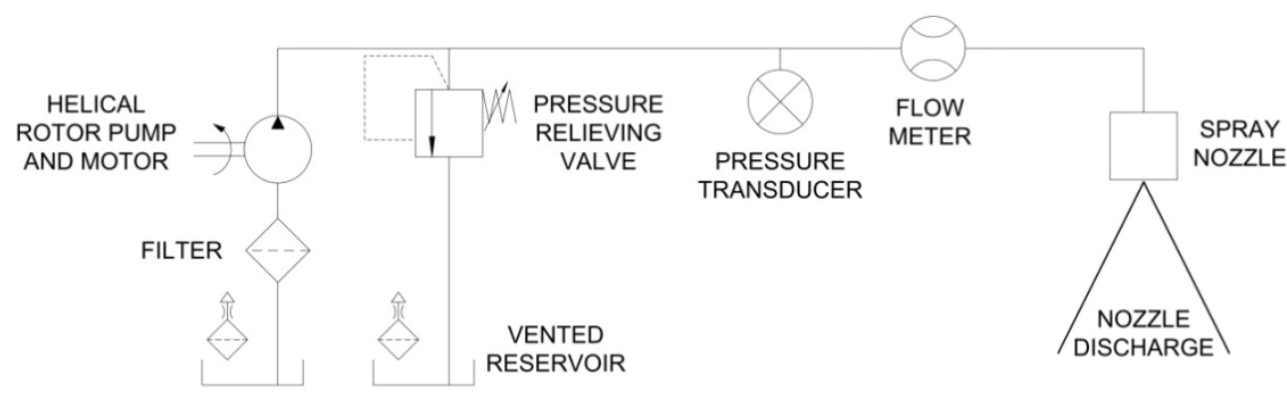

Figure 2. System schematic for variable-orifice nozzle response testing. 


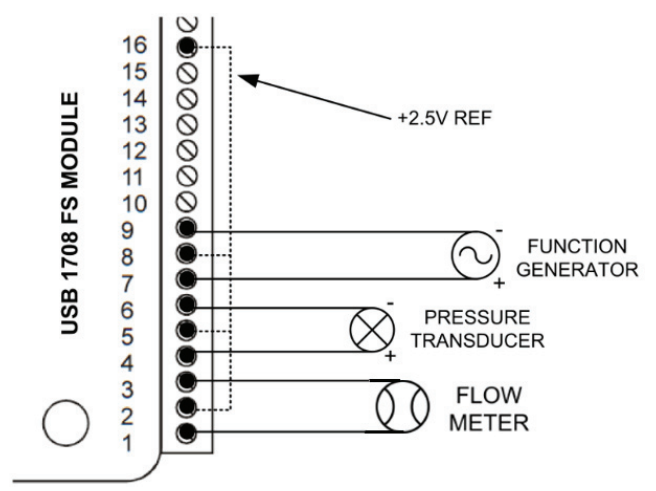

Figure 3. Schematic of circuit to integrate data acquisition module for data collection and nozzle operation.

mated from previous work by Luck et al. (2010) in which air pressure controlled the metering stem. The end of the actuating rod was threaded into the metering stem. A stepper-motor controller (STP100, Pontech, Rancho Cucamonga, Cal.) was used to control the linear actuator position via the computer serial port and was provided with 7 VDC from an external power supply. Actuator extension and retraction were directly proportional to the number of motor steps (MS), with a minimum time of $0.675 \mathrm{~s}$ required for the actuator to travel 400 motor steps. Operational setup of the stepper-motor controller included a step delay of 800 $\mu \mathrm{s}$ with power constantly supplied to the motor coils during operation per manufacturer specifications (Pontech, 1997). The nozzle was controlled using a custom software interface that was written in Microsoft Visual Studio 2010. The software provided manual control of the linear actuator whereby the desired metering stem position (in MS) was entered into the user interface. In addition, the control program provided an option for automatic mode to reposition the linear actuator (up to $15 \mathrm{~Hz}$ ) based on a selected external input (function generator).

Data acquisition was accomplished using a USB-based analog and digital I/O module (USB-1408FS, Measurement Computing, Inc., Norton, Mass.) connected to a desktop computer. The data acquisition module was used to record voltage output from the pressure transducer and the flowmeter. In addition, the module recorded voltage output from a function generator (8116A pulse/function generator $50 \mathrm{MHz}$, Hewlett Packard, Palo Alto, Cal.) used during frequency and ramp response testing. The module operated in four-channel differential mode (MicroDAQ, 2011) to record the desired data, as shown in figure 3.

\section{Closed-Loop Test Procedures and ANALysis Step Response Analysis}

The system was tested at carrier pressures of 138, 207, 276,345 , and $414 \mathrm{kPa}$. The desired initial test flow rate $\left(Q_{i n}\right)$ was set at minimum $\left(Q_{\min }\right)$ and maximum $\left(Q_{\max }\right)$ to allow the metering stem to be positioned between 400 and 800 MS. Values of $Q_{\min }$ and $Q_{\max }$ are summarized in table 1 for the five operating pressures. Two test flow rate values of 1.21 and $2.95 \mathrm{~L} \mathrm{~min}^{-1}\left(Q_{\min }\right.$ and $Q_{\max }$ at $207 \mathrm{kPa}$, respectively) were entered into the user interface after the program was set for automatic mode. $Q_{i n}$ represented a set point for the nozzle controller to achieve by adjusting the
Table 1. $Q_{\min }$ and $Q_{\max }$ settings for closed-loop step response tests.

\begin{tabular}{ccc}
\hline $\begin{array}{c}\text { Pressure } \\
(\mathrm{kPa})\end{array}$ & $\begin{array}{c}Q_{\min } \\
\left(\mathrm{L} \mathrm{min}^{-1}\right)\end{array}$ & $\begin{array}{c}Q_{\max } \\
\left(\mathrm{L} \mathrm{min}^{-1}\right)\end{array}$ \\
\hline 138 & 0.95 & 2.27 \\
207 & 1.21 & 2.95 \\
276 & 1.48 & 3.56 \\
345 & 1.78 & 4.32 \\
414 & 2.08 & 5.00 \\
\hline
\end{tabular}

metering stem position for conducting a step response analysis. As previously discussed, feedback consisted of the actual flow rate values (analog output) from the flowmeter, which updated at a rate of $15 \mathrm{~Hz}$. The flow rate error was calculated by differencing $Q_{i n}$ and the actual flow rate $\left(Q_{o}\right)$ values. The control program operated by using a proportional gain to adjust the metering stem position (from 400 to $800 \mathrm{MS}$ ) based on the flow rate error. The closed-loop proportional gain $(K)$ was varied from 50 to 1000 to determine values of $K$ for which the system response changed from overdamped to underdamped.

During each test, $Q_{i n}$ was set (e.g., at $Q_{\min }$ ) and the system was allowed 5 to $10 \mathrm{~s}$ to stabilize. Then $Q_{i n}$ was changed to $Q_{\max }$ and another 5 to $10 \mathrm{~s}$ passed. This process was repeated at least five times for each $K$ value tested. During these periods, the time, $Q_{i n}, Q_{o}$, and system pressure were recorded by the control program. At the end of each test, these data were exported into a text file for later analysis. It should be noted that as a safety precaution, the operational range of the metering stem in automatic mode was limited to 400 to $800 \mathrm{MS}$. This was achieved via the control program to maintain flow rates within the linear operating range of the nozzle, as reported by Luck et al. (2015), and to protect the nozzle from damage from overextension of the metering stem (above $800 \mathrm{MS}$ ).

Closed-loop step response analyses generally followed the steps outlined by Nise (2008). The desired and actual flow rate values were plotted versus time for each value of $K$ tested. Parameters that were determined from these plots included settling time $\left(t_{s}\right)$, rise time $\left(t_{r}\right)$, peak time $\left(t_{p}\right)$, and overshoot $(O S)$. The goal of this portion of the study was to determine if a second-order transfer function $(G(s)$ in eq. 1) for the system could be found. MATLAB was used to simulate the transfer function response to see if the system could be modeled. The general form of the second-order equation is given as:

$$
G(s)=\frac{\omega_{n}^{2}}{s^{2}+2 \zeta \omega_{n}^{2} s+\omega_{n}^{2}}
$$

where $\omega_{n}$ is the natural frequency, and $\zeta$ is the damping ratio.

The parameters $\omega_{n}$ and $\zeta$ represent the transient response characteristics of the second-order system and can be estimated from equations 2 and 3 for known values of $t_{s}, t_{r}$, and $t_{p}$, as discussed by Nise (2008):

$$
t_{p}=\frac{\pi}{\omega_{n} \sqrt{1-\zeta^{2}}}
$$




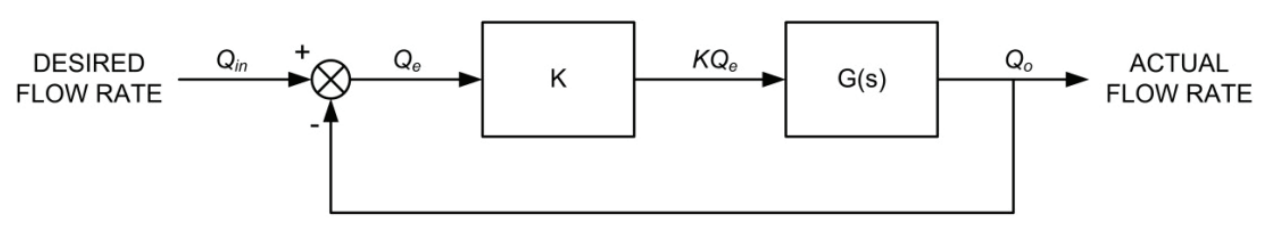

Figure 4. Generalized block diagram of nozzle control system.

$$
t_{s}=\frac{4}{\zeta \omega_{n}}
$$

For an overdamped system, values of $t_{p}$ do not exist, as there is no $O S$ observed in the system response. The method for estimating $t_{r}$ was from Dorf and Bishop (2008):

$$
t_{r}=\frac{2.16 \zeta+0.60}{\omega_{n}}
$$

The parameters $\omega_{n}$ and $\zeta$ were therefore estimated by simultaneously solving two of these equations (eqs. 2, 3, and 4$)$. The locations of the system poles $\left(s_{1,2}\right)$ could then be calculated using equation 5 :

$$
s_{1,2}=-\zeta \omega_{n} \pm \omega_{n} \sqrt{\zeta^{2}-1}
$$

A block diagram identifying the general operation of the closed-loop system is shown in figure 4.

Ultimately, nozzle response characteristics chosen for system evaluation included the $t_{s}, O S$, and steady-state error $\left(e_{s s}\right)$ of the system. The goal was to find a control system (proportional control of gain $K$ ) that would result in a fast response time with low $e_{s s}$ to minimize off-rate pesticide application. While response characteristics including $t_{s}$ and $e_{s s}$ are typically evaluated based on the desired set point $\pm 2 \%$ for control systems analyses, sprayer control systems have not typically been designed to meet such constraints. Based on previous studies for nozzle development by Han et al. (1986) and sprayer control system evaluation by Reitz et al. (1997), $t_{s}$ was calculated for values of $Q_{o}$ upon reaching $\pm 5 \%$ of $Q_{i n}$. After the $t_{s}$ had been achieved, the absolute difference between $Q_{o}$ values and $Q_{\text {in }}$ were averaged (up until the next step input) to determine the value of $e_{s s}$. Values of $t_{s}$ were calculated as the time when $Q_{i n}$ was set until values of $Q_{o}$ reached and were maintained at $Q_{\text {in }} \pm 5 \%$. The system $O S$ in each situation was to be maintained less than $10 \%$ of $Q_{i n}$.

\section{Ramp Response Analysis}

The closed-loop ramp response analysis followed procedures similar to the step response analysis previously discussed. Using the proportional $K$ control system developed from the closed-loop step response analysis, the system was tested at carrier pressures of 138, 207, 276, 345, and $414 \mathrm{kPa}$. The function generator was used to provide 0 to $5 \mathrm{VDC}$ as a ramp input to the module. The control program scaled the input from the function generator into the available output range for the nozzle with 0 to $5 \mathrm{VDC}$ (0 to $16383 \mathrm{~A} / \mathrm{D}$ counts from the DAQ board) corresponding to values of $Q_{\min }$ and $Q_{\max }$ in table 1, respectively, using equation 6 to calculate $Q_{i n}$ :

$$
Q_{\text {in }}=\left(Q_{\max }-Q_{\text {min }}\right) \times \frac{(\mathrm{A} / \text { Dcount }}{16383}+Q_{\text {min }}
$$

The function generator output was recorded at $15 \mathrm{~Hz}$, and the control program was set to automatic mode such that the function generator output represented $Q_{i n}$. The function generator produced frequencies ranging from 0.02 to $0.2 \mathrm{~Hz}$ to provide a ramp input to the system. During each test, the time, $Q_{i n}$, and $Q_{o}$ were recorded into a text file. These data were then imported into Microsoft Excel to conduct the analysis. During the tests, it was noticed that periodically $(\sim 25 \mathrm{~s})$ the current output from the flowmeter dropped to $0 \mathrm{~mA}$ for approximately $1 \mathrm{~s}$. Interaction with manufacturer engineers and technicians failed to resolve this issue. The only recourse was to eliminate these periods from the ramp response analysis for calculating lag times and the error between $Q_{\text {in }}$ and $Q_{o}$.

The time lag for $Q_{o}$ to achieve $Q_{\text {in }}$ was also estimated by calculating the absolute error between the two and calculating the sum of the squared errors (SSE). The $Q_{o}$ values were shifted by one sampling period $(0.067 \mathrm{~s})$, and the SSE was calculated again. This process was repeated until the minimum SSE was found for each dataset. While this was a straightforward process for determining nozzle lag time, the estimate could vary $\pm 0.034 \mathrm{~s}$.

In most cases, nozzle response evaluations end at the estimation of lag time. However, the error analyses proceeded by seeking to evaluate the magnitude of the error in addition to any lag time. The absolute error between $Q_{i n}$ and $Q_{o}$ was also calculated at each data point to determine the magnitude of the error between the desired and actual flow rates. The average of the absolute error was calculated for each input frequency from $10 \%$ to $90 \%$ of $Q_{i n}$.

The goal was to determine the maximum frequency at which the control system could compensate for changes in the desired flow rate based on two constraints: the average absolute error should not exceed $5 \%$ over the course of one cycle, and the average absolute error plus two standard deviations $(\sigma)$ should not exceed $10 \%$ of $Q_{i n}$. This ensured that the nozzle would operate within specifications at least $95 \%$ of the time, allowing some room for any errors during data acquisition. The average absolute change in $Q_{\text {in }}\left(\Delta Q_{i n}\right)$ was also calculated for each ramp input frequency to determine the maximum rate at which the nozzle would respond within the desired specifications.

\section{RESULTS AND DISCUSSION}

\section{STEP RESPONSE ANALYSIS}

An example of the preliminary closed-loop step response data is shown in figure 5 . The data were collected at a carrier pressure of $207 \mathrm{kPa}$ with $K$ equal to 100 . These 


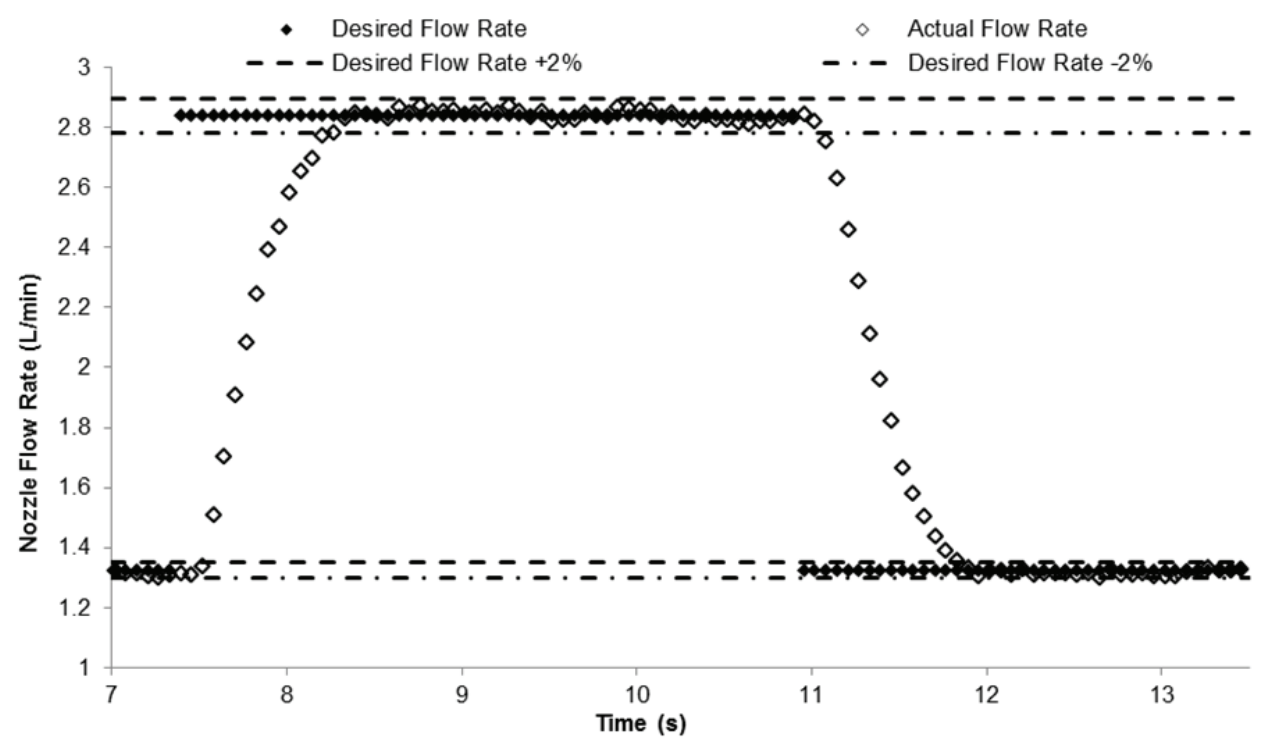

Figure 5. Flow rate versus time for closed-loop step response (207 kPa, $K=100)$.

data represent two steps: one from $Q_{\min }$ to $Q_{\max }$ at $7.5 \mathrm{~s}$, and from $Q_{\max }$ to $Q_{\min }$ at $11 \mathrm{~s}$. Because the system response appeared to be overdamped, $t_{p}$ could not be used to estimate values of $\omega_{n}$ and $\zeta$; however, $t_{s}$ and $t_{r}$ were identifiable from the data contained in figure 5. Average values of $t_{s}$ and $t_{r}$ were calculated as 0.91 and $0.55 \mathrm{~s}$, respectively. Equations 3 and 4 were solved simultaneously with these values for $t_{s}$ and $t_{r}$, which produced estimates for $\omega_{n}$ and $\zeta$ of 5.0 and 1.0, respectively. The preliminary closed-loop analysis also yielded other important information regarding system performance by estimating the value of $\zeta$ at 1.0 . This implied that for a $K$ of 100 , the system was critically damped, which reinforced the visual inspection of the data contained in figure 5. The steady-state response of the system appeared to stay within the range of $\pm 2 \%$ of the $Q_{\max }$ and $Q_{\min }$ values used during the test, as shown in figure 6 .
The average $e_{s s}$ during this test was $0.47 \%$ of $Q_{\max }$ and $0.87 \%$ of $Q_{\text {min }}$.

Based on control systems theory, decreasing the value of $K$ would lead the closed loop system to be more highly overdamped, an example of which can be seen in figure 6 . Here, $K$ was decreased from 100 to 50 with the system operating pressure at $207 \mathrm{kPa}$. The delayed response is evident in comparison to figure 5; the value of $t_{s}(>3 \mathrm{~s})$ for a $K$ value of 50 was much higher than $t_{s}$ for $K$ of $100(<1 \mathrm{~s})$ with no system $O S$ noticed. Conversely, if $K$ were to be increased above 100 , the system would likely begin to exhibit an underdamped response characterized by overshoot. An example of this response can be seen in figure 7, where $K$ was increased to 500 with the operating pressure at $207 \mathrm{kPa}$. Here, the system response continued to oscillate around the value of $Q_{i n}$ and did not completely settle during the test run.

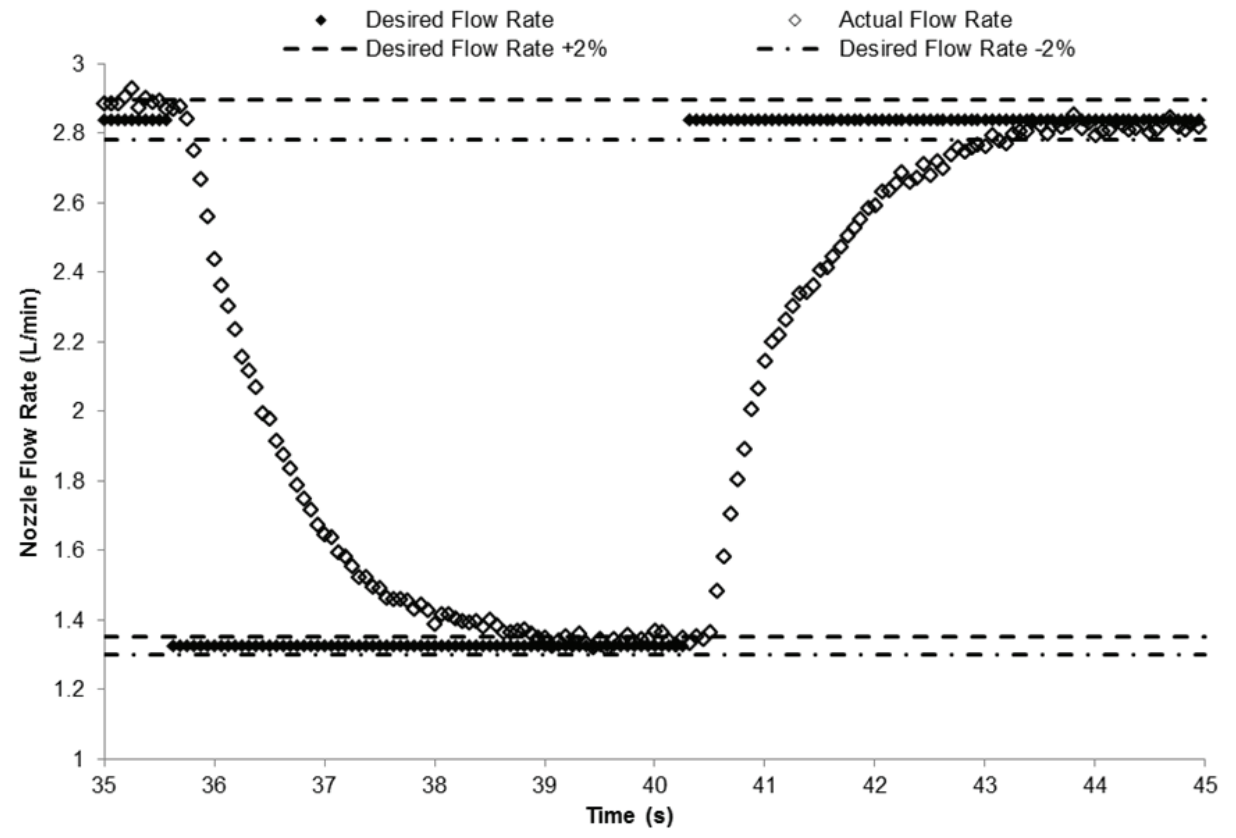

Figure 6. Flow rate versus time for closed-loop step response ( $207 \mathrm{kPa}, K=50)$. 


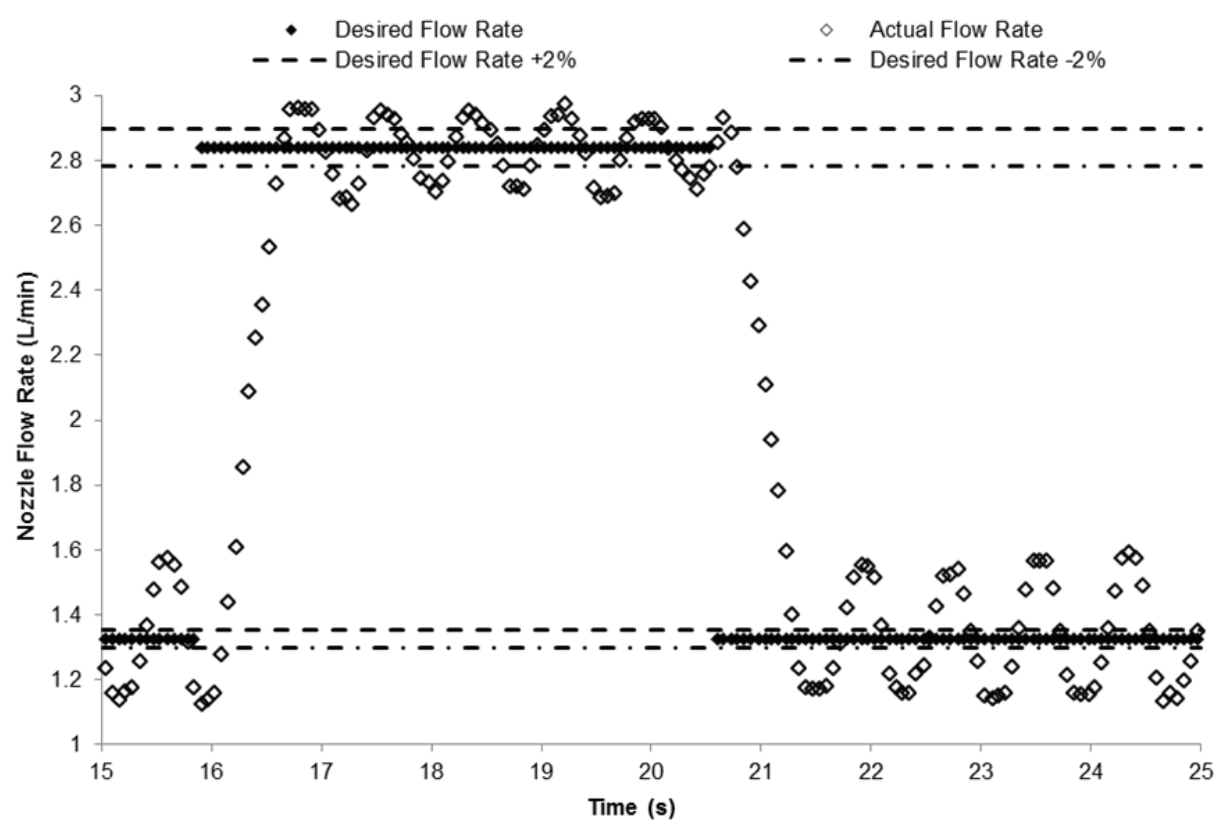

Figure 7. Flow rate versus time for closed-loop step response ( $207 \mathrm{kPa}, K=500)$.

Simulations were conducted in MATLAB (step function) and revealed that the system should be stable at $K$ values greater than 10,000 . However, the data shown in figure 7 clearly indicate that the system became unstable as $K$ was increased above 500 . Comparisons of the actual system response with the simulation data revealed two features of the test data that may explain why the simulations were inaccurate. First, for a specific $K$ value, the system response varied between test pressures. For example, at $137 \mathrm{kPa}$, setting $K$ equal to 100 resulted in a nearly critically damped system response. At $414 \mathrm{kPa}$, the same $K$ setting resulted in an underdamped response with an $O S$ greater than $10 \%$. This was likely due to the relationship between pressure and flow being nonlinear for nozzles. Second, it was noted that the system response was not necessarily the same as the metering stem was extending or retracting for a specific $K$. This hysteresis effect may be attributed to stiction or forces acting on the metering stem inside the nozzle from the carrier pressures. Carrier pressures generate opposing forces against the metering stem (and diaphragm) during extension, while these forces act in the direction of travel during metering stem retraction. Equations were developed to calculate $K$ based on pressure for metering stem retraction $\left(K_{r e t}\right)$ or extension $\left(K_{e x t}\right)$. While efforts to model the system as a simple second-order system did not adequately predict changes, further work in this area could help optimize the system performance. While not a specific objective of this particular study, modeling would allow for improving predictive capacity of changes within the system and should be considered in the future.

The decision was made to empirically develop a proportional nozzle control system with variable $K$ based on the data collected for the five test pressures and values of $K$ ranging from 50 to 1000 . As previously discussed, one de- sired operational characteristic was to minimize the $t_{s}$ of the response $\left( \pm 5 \%\right.$ of $\left.Q_{i n}\right)$. Achieving a $t_{s}$ of less than $0.675 \mathrm{~s}$ for a full step would be difficult because of the actuator speed limit (400 to $800 \mathrm{MS}$ in $0.675 \mathrm{~s}$ ). Therefore, the goal was to maintain $t_{s}$ values below $1 \mathrm{~s}$ for a step change from $Q_{\min }$ to $Q_{\max }$ and vice versa. Realizing that a critically damped system would not react as quickly as an underdamped system, the decision was made to allow system $O S$ below $10 \%$ with $e_{s s}$ not exceeding $2 \%$ of $Q_{i n}$.

Visual inspection of the data collected from 138 to $414 \mathrm{kPa}$ with $K$ ranging from 50 to 1000 indicated that the relationship between $K$ and system pressure $(P)$ was not necessarily linear. This was verified by plotting approximate values for $K$ versus $P$ (138 to $414 \mathrm{kPa}$ ) that resulted in a critically damped system response from the initial data collected (fig. 8). A polynomial regression equation was fit to the data to estimate a value for $K_{r e t}$ and $K_{\text {ext }}$ based on the current system operating pressure. As previously discussed, a system response with some $O S$ would be acceptable, as this would result in a reduced settling time compared to a critically damped system. Five trial runs were conducted using the expressions for $K_{r e t}$ and $K_{e x t}$ in the control program. After each trial, adjustments were made to the equations for $K_{r e t}$ and $K_{e x t}$ to improve the system response for the system pressures tested with step inputs provided in table 1 . Finally, a set of equations was developed to achieve the desired system response characteristics $\left(t_{s}<1 \mathrm{~s}, O S<\right.$ $10 \%$, and $e_{s s}<2 \%$ ) for system pressures ranging from 138 to $414 \mathrm{kPa}$. Formulas for calculating $K_{\text {ret }}$ and $K_{\text {ext }}$ are shown in equations 7 and 8 , respectively:

$$
\begin{aligned}
& K_{\text {ret }}=0.000253 P^{2}-0.341 P+172.8 \\
& K_{\text {ext }}=0.000595 P^{2}-0.535 P+188.8
\end{aligned}
$$




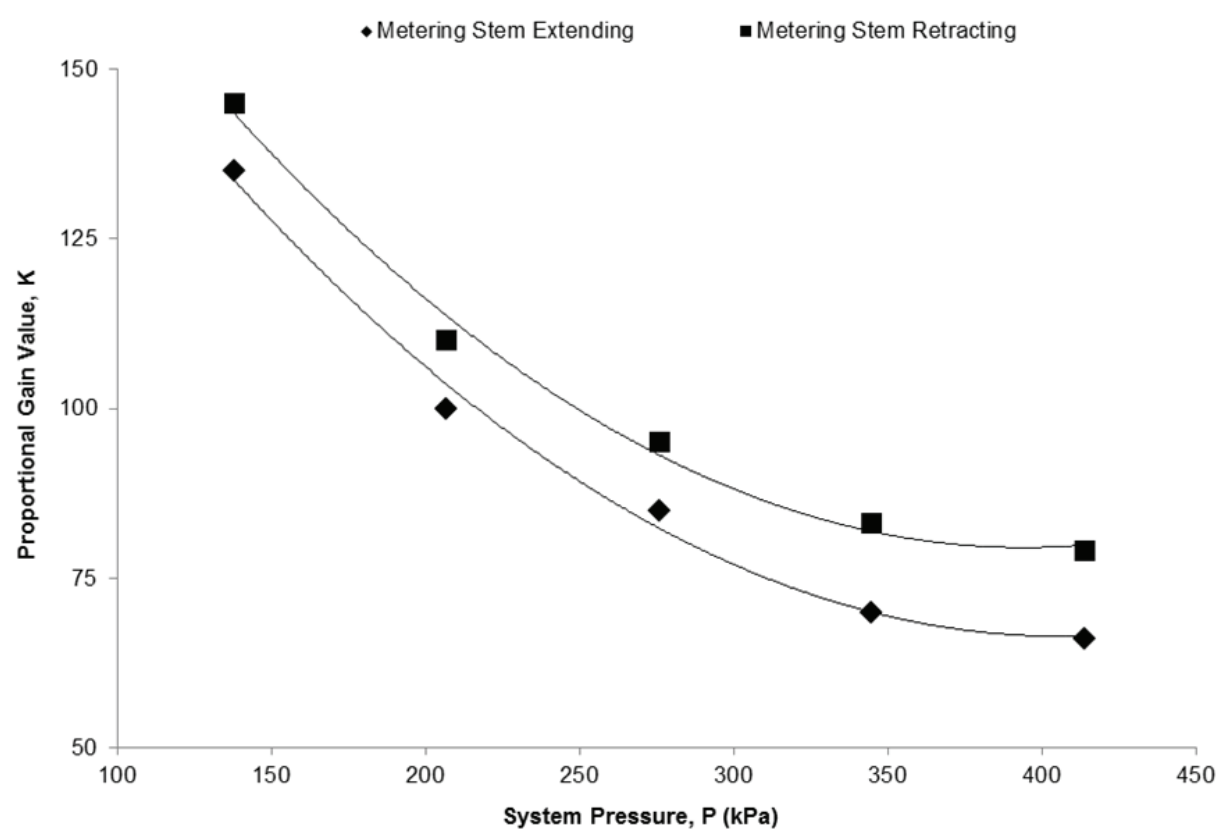

Figure 8. Values of proportional gain $(K)$ plotted versus system pressure $(P)$ that resulted in a critically damped system response.

The final closed-loop test trial was conducted using equations 7 and 8 with the step inputs in table 1 . The analyses to determine $t_{s}, O S$, and $e_{s s}$ were conducted separately for $Q_{i n}$ settings between $Q_{\min }$ and $Q_{\max }$ to ensure that the control system would work properly regardless of actuator travel direction. System response characteristics for the five carrier pressures are summarized in tables 2 and 3 for $K_{\text {ret }}$ and $K_{e x t}$, respectively.

The response characteristics were acceptable for the control system as the step input was changed from $Q_{\min }$ to $Q_{\max }$ (table 2). The $t_{s}$ values were less than $1 \mathrm{~s}, O S$ was below $10 \%$ of $Q_{\max }$, and $e_{s s}$ was below $2 \%$ for all five test pressures. Some improvement could have been made for the nozzle at $276 \mathrm{kPa}$, which exhibited the least desirable response in the final trials. A slight decrease in the $K_{r e t}$ value at this pressure (and subsequent recalculation of the equation for $K_{r e t}$ ) would likely solve this issue. However, the system response characteristics were still within the satisfactory range for these values; therefore, the results were considered acceptable.

The system response characteristics for the step input change from $Q_{\max }$ to $Q_{\min }$ are summarized in table 3. Simi-

Table 2. Closed-loop system response with variable $K_{r e t}$ control.

\begin{tabular}{ccccc}
\hline $\begin{array}{c}\text { Pressure } \\
(\mathrm{kPa})\end{array}$ & $\begin{array}{c}t_{s} \\
(\mathrm{~s})\end{array}$ & $\begin{array}{c}O S \\
\left(\% Q_{\max }\right)\end{array}$ & $\begin{array}{c}e_{s s} \\
\left(\% Q_{\max }\right)\end{array}$ & $\begin{array}{c}K_{\text {ret }} \\
(\text { avg. })\end{array}$ \\
\hline 138 & 0.63 & 2.6 & 1.0 & 130 \\
207 & 0.71 & 5.3 & 1.1 & 115 \\
276 & 0.96 & 7.2 & 1.5 & 98 \\
345 & 0.73 & 3.3 & 1.2 & 85 \\
414 & 0.74 & 2.5 & 1.2 & 76 \\
\hline
\end{tabular}

Table 3. Closed-loop system response with variable $K_{e x t}$ control.

\begin{tabular}{ccccc}
\hline $\begin{array}{c}\text { Pressure } \\
(\mathrm{kPa})\end{array}$ & $\begin{array}{c}t_{s} \\
(\mathrm{~s})\end{array}$ & $\begin{array}{c}O S \\
\left(\% Q_{\min }\right)\end{array}$ & $\begin{array}{c}e_{s s} \\
\left(\% Q_{\min }\right)\end{array}$ & $\begin{array}{c}K_{\text {ext }} \\
(\text { avg. })\end{array}$ \\
\hline 138 & 0.75 & 2.4 & 0.83 & 125 \\
207 & 0.75 & 1.7 & 1.6 & 106 \\
276 & 0.79 & 2.3 & 1.1 & 85 \\
345 & 0.79 & 3.1 & 1.8 & 73 \\
414 & 0.8 & 2.1 & 1.3 & 70 \\
\hline
\end{tabular}

lar to the previous discussion, the $t_{s}$ values were less than $1.0 \mathrm{~s}, O S$ was below $10 \%$ of $Q_{\max }$, and $e_{s s}$ was below $2 \%$ for all five test pressures using equation 8 for $K_{\text {ext }}$. Values for $t_{s}$ were similar for all pressures, ranging between 0.75 and $0.80 \mathrm{~s}$. The system $O S$ was less than $3.1 \%$ of $Q_{\min }$, and $e_{s s}$ was less than $2 \%$ for all test pressures, indicating that the system response characteristics were acceptable.

An example test cycle for the variable $K$ control system (eqs. 7 and 8) operated at a carrier pressure of $138 \mathrm{kPa}$ is shown in figure 9. Similar test cycles were performed for the other four carrier pressure settings. In figure 9, it is possible to see the point at which the flow rate command $\left(Q_{i n}\right)$ switched from $Q_{\min }$ to $Q_{\max }$ (or vice versa). Also included are the values of $Q_{i n} \pm 5 \%$ (for determining $t_{s}$ ) and $\pm 10 \%$ (for calculating $O S$ ). For all tests, the system with $K_{\text {ret }}$ $\left(Q_{\text {in }}=Q_{\max }\right)$ exhibited a noticeably underdamped response to the step input. When $Q_{i n}$ was set to $Q_{\min }$, the response was only slightly underdamped ( $O S>1.7 \%$ in all cases). However, there were definitely less oscillations as the $Q_{o}$ settled after the step input. It is difficult to say whether one case would be better than the other, as both displayed acceptable response characteristics, specifically with regard to the similar $t_{s}$ and $e_{s s}$ values in both situations.

In the end, the variable $K$ control system seemed to perform well in comparison to the response constraints placed on the system using proportional control. Integral control was deemed unnecessary because the $e_{s s}$ values were not considered significant. This was likely due to the resolution available from the stepper motor (400 MS) for the limited flow rate ranges required. Derivative control was not considered because proportional control yielded $t_{s}$ values that were slightly greater than the time required for the actuator to complete a full step $(0.675 \mathrm{~s})$ and response times were satisfactory.

\section{RAMP RESPONSE ANALYSIS}

The ramp response tests were conducted to determine 


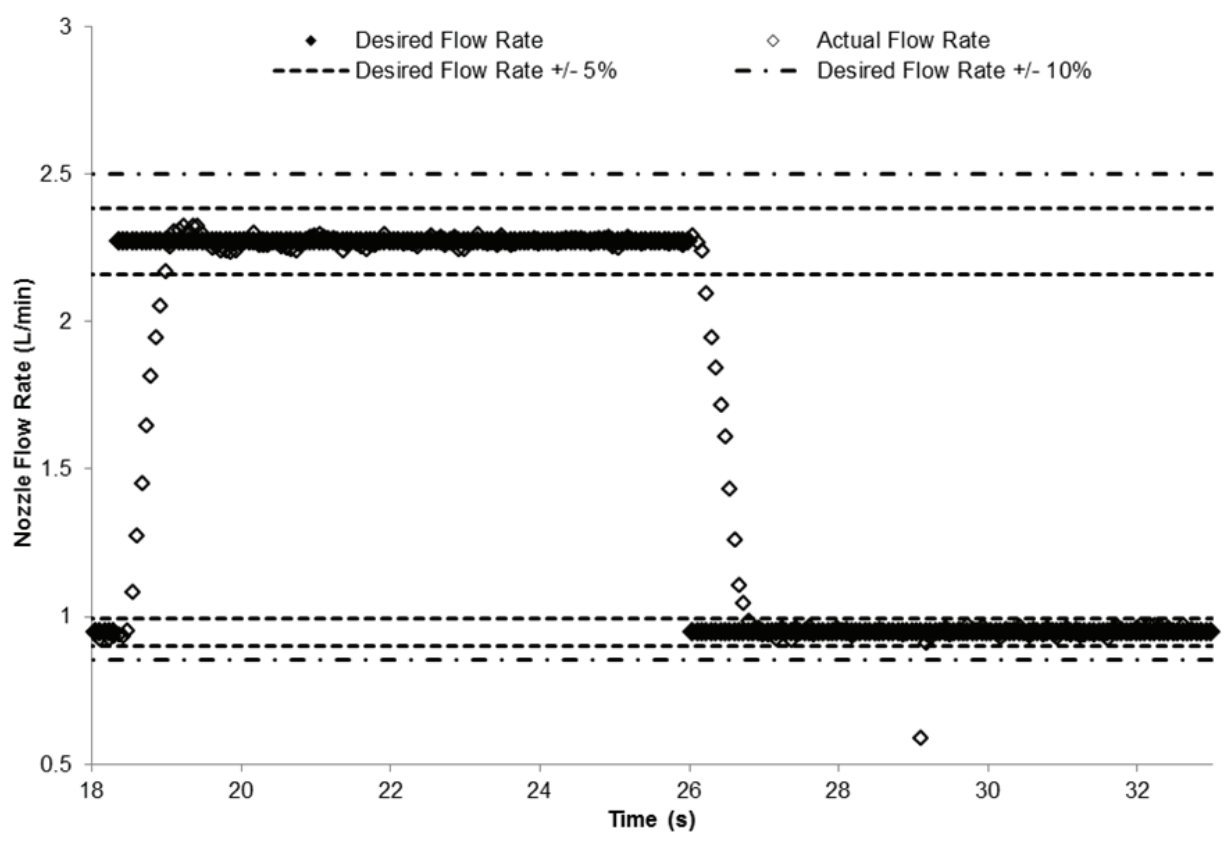

Figure 9. Closed-loop step response with variable $K$ control (138 kPa).

how the variable $K$ control system developed from the closed-loop step response tests would respond to a constantly changing value of $Q_{i n}$, in this case a ramp input. The goal was to determine the maximum frequency or rate of change in the input at which the nozzle could operate and remain within the desired response characteristics. A summary of these values for the ramp response tests is shown in table 4 . The data in table 4 demonstrate a direct relationship between the input frequency and the average absolute error between $Q_{i n}$ and $Q_{o}$ at all five carrier test pressures. The same relationship was seen with input frequency and

Table 4. Closed-loop ramp response with variable $K$ control.

\begin{tabular}{|c|c|c|c|c|c|}
\hline $\begin{array}{c}\text { Pressure } \\
(\mathrm{kPa})\end{array}$ & $\begin{array}{l}\text { Frequency } \\
(\mathrm{Hz})\end{array}$ & $\begin{array}{c}\text { Average } \\
\text { Absolute } \\
\text { Error } \\
(\%)\end{array}$ & $\begin{array}{c}\text { Average } \\
\text { Absolute } \\
\text { Error }+2 \sigma \\
(\%)\end{array}$ & $\begin{array}{c}\text { Lag } \\
\text { Time } \\
\pm 0.067 \mathrm{~s} \\
\text { (s) }\end{array}$ & $\begin{array}{c}\text { Average } \\
\Delta Q_{\text {in }} \\
\left(\mathrm{mL} \mathrm{s}^{-2}\right)\end{array}$ \\
\hline \multirow[t]{5}{*}{138} & 0.02 & 1.7 & 4.1 & 0.439 & 0.854 \\
\hline & 0.05 & 3.4 & 6.8 & 0.251 & 2.12 \\
\hline & 0.07 & 4.6 & 8.5 & 0.25 & 2.97 \\
\hline & 0.10 & 6.9 & 12.5 & 0.432 & 4.26 \\
\hline & 0.20 & 13.7 & 22.9 & 0.378 & 8.43 \\
\hline \multirow[t]{5}{*}{207} & 0.02 & 1.6 & 3.7 & 0.301 & 1.08 \\
\hline & 0.05 & 3.4 & 6.1 & 0.373 & 2.69 \\
\hline & 0.07 & 4.8 & 8.5 & 0.31 & 3.77 \\
\hline & 0.10 & 7.4 & 13.1 & 0.437 & 5.40 \\
\hline & 0.20 & 16.2 & 45.3 & 0.496 & 10.7 \\
\hline \multirow[t]{5}{*}{276} & 0.02 & 1.8 & 5.8 & 0.311 & 1.29 \\
\hline & 0.05 & 3.5 & 6.5 & 0.375 & 3.22 \\
\hline & 0.07 & 5.0 & 8.9 & 0.364 & 4.50 \\
\hline & 0.10 & 7.7 & 15.4 & 0.423 & 6.44 \\
\hline & 0.20 & 14.4 & 25.7 & 0.432 & 12.8 \\
\hline \multirow[t]{5}{*}{345} & 0.02 & 1.7 & 3.9 & 0.372 & 1.60 \\
\hline & 0.05 & 4.0 & 9.1 & 0.373 & 3.98 \\
\hline & 0.07 & 4.9 & 9.0 & 0.377 & 5.56 \\
\hline & 0.10 & 7.7 & 16.0 & 0.378 & 7.96 \\
\hline & 0.20 & 14.4 & 25.0 & 0.431 & 15.8 \\
\hline \multirow[t]{5}{*}{414} & 0.02 & 1.7 & 3.8 & 0.311 & 1.84 \\
\hline & 0.05 & 3.9 & 7.7 & 0.374 & 4.57 \\
\hline & 0.07 & 4.9 & 9.9 & 0.311 & 6.39 \\
\hline & 0.10 & 7.3 & 14.0 & 0.422 & 9.15 \\
\hline & 0.20 & 13.3 & 25.9 & 0.497 & 18.1 \\
\hline
\end{tabular}

the average absolute error $+2 \sigma$. As previously discussed, the response was considered unacceptable if the average absolute error between $Q_{i n}$ and $Q_{o}$ exceeded $5 \%$ or the average absolute error $(+2 \sigma)$ exceeded $10 \%$. The maximum acceptable operating frequency was $0.07 \mathrm{~Hz}$ at each carrier pressure based on these specifications.

Lag times for the nozzle response using the variable $K$ control system were better than expected. At each operating frequency and carrier pressure, lag times did not exceed $0.5 \mathrm{~s}$ (although the error in these measurements could have been as much as $\pm 0.034 \mathrm{~s}$, as previously discussed). At $0.07 \mathrm{~Hz}$, response lag times ranged from 0.250 to $0.377 \mathrm{~s}$. When considering the previously mentioned lag time errors, these results are more than acceptable, as lag times were less than $1.0 \mathrm{~s}$. These results also show the potential for misrepresenting results of an analysis focused solely on evaluating lag time. As demonstrated by past studies (Sudduth et al., 1995; Rockwell and Ayers, 1996; Vondricka and Schulze Lammers, 2009), nozzle response lag times are often reported, while the cumulative error with the delay in achieving an acceptable application rate is rarely stated. The results in table 4 show that while the lag times may be considered acceptable, the error magnitude may not.

Results of the ramp response tests also provided average $\Delta Q_{i n}$, a crucial piece of information related to the operational capabilities of the system. Values of $\Delta Q_{i n}$ for the maximum acceptable operating frequency $(0.07 \mathrm{~Hz})$ ranged from 2.97 to $6.39 \mathrm{~mL} \mathrm{~s}^{-2}$ for pressures ranging from 138 to $414 \mathrm{kPa}$, respectively. These data suggest limits for maximum application rate change that the nozzle control system was able to consistently handle. As expected, the control system was able to compensate for greater changes as operating pressure increased.

The resulting sprayer acceleration values (table 5) were calculated based on the average $\Delta Q_{i n}$ for each operating pressure at $0.07 \mathrm{~Hz}$. As the operating pressure increased, the nozzle control system compensated for accelerations up 
Table 5. Maximum sprayer acceleration rates derived from ramp response test results $\left(0.51 \mathrm{~m}\right.$ nozzle width at $\left.93.5 \mathrm{~L} \mathrm{ha}^{-1}\right)$.

\begin{tabular}{ccc}
\hline $\begin{array}{c}\text { Pressure } \\
(\mathrm{kPa})\end{array}$ & $\begin{array}{c}\text { Average } \Delta Q_{\text {in }} \\
\left(\mathrm{mL} \mathrm{s}^{-2}\right)\end{array}$ & $\begin{array}{c}\text { Acceleration } \\
\left(\mathrm{m} \mathrm{s}^{-2}\right)\end{array}$ \\
\hline 138 & 2.97 & 0.625 \\
207 & 3.77 & 0.793 \\
276 & 4.50 & 0.946 \\
345 & 5.56 & 1.17 \\
414 & 6.39 & 1.34 \\
\hline
\end{tabular}

to $1.34 \mathrm{~m} \mathrm{~s}^{-1}$ for extended periods of time. It should be noted that these values hold true for an application rate of 93.5 $\mathrm{L} \mathrm{ha}^{-1}$. Reducing the target rate would allow compensation for greater acceleration. Alternately, increasing the target application rate would reduce the ability of the nozzle to compensate for acceleration.
Based on the case study results published by Luck et al. (2011), the average sprayer acceleration presented was $0.4 \mathrm{~m}$ $\mathrm{s}^{-2}$, while $95 \%$ of the acceleration values ranged from 0 to $1.75 \mathrm{~m} \mathrm{~s}^{-2}$. These findings suggest that the nozzle control system would meet performance specifications for average case study acceleration values for the example shown in table 5 . The system may not be able to compensate for extended periods of acceleration at peak values (nearing $1.75 \mathrm{~m} \mathrm{~s}^{-2}$ ). In general, an operating pressure would likely be chosen based on nozzle type and expected sprayer velocity.

Figure 10 shows the ramp response tests for a carrier pressure of $138 \mathrm{kPa}$ with an input frequency of $0.07 \mathrm{~Hz}$. $Q_{o}$ tracked but did not exceed $Q_{i n} \pm 10 \%$ for the duration of the tests, with an average absolute error of $4.6 \%$. Figure 11 shows a similar test at $138 \mathrm{kPa}$ with a $Q_{\text {in }}$ frequency of

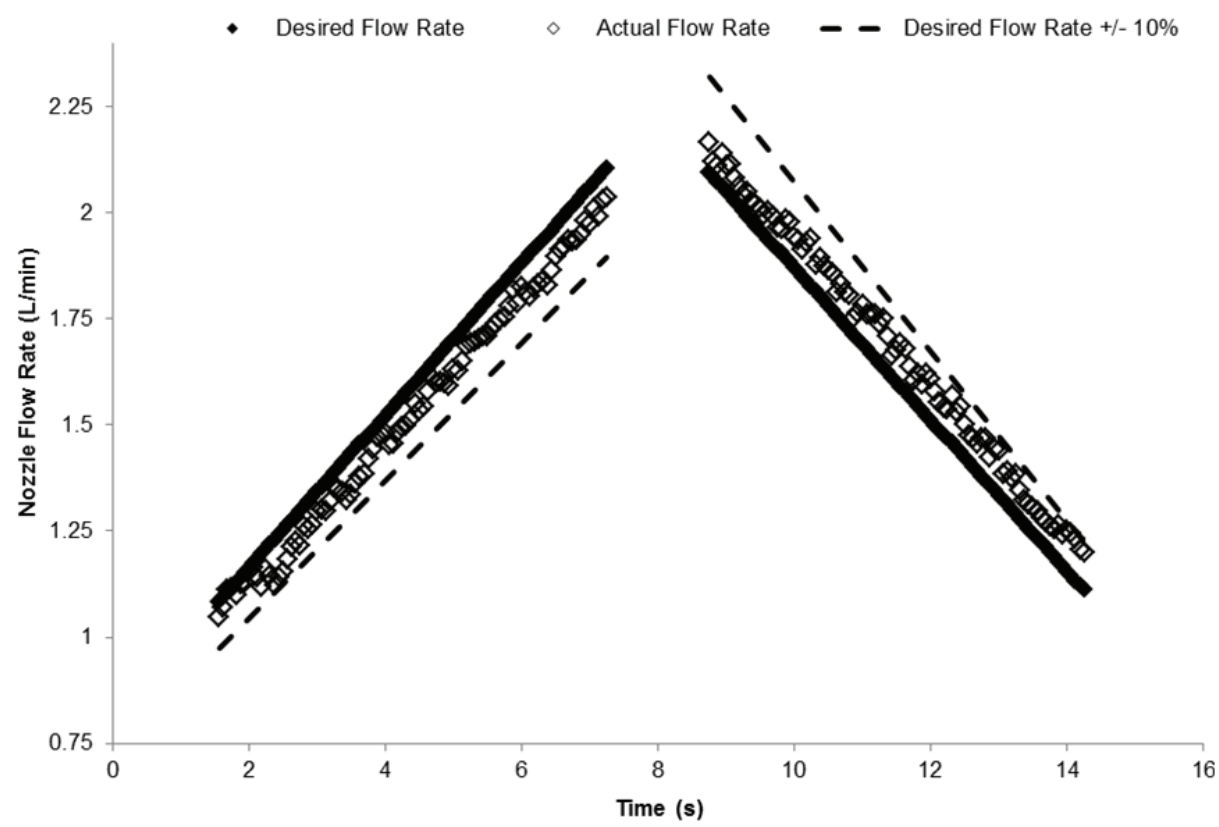

Figure 10. Ramp response of variable $K$ nozzle control at $138 \mathrm{kPa}$ and $0.07 \mathrm{~Hz}$.

- Desired Flow Rate $\quad \diamond$ Actual Flow Rate _ - Desired Flow Rate $+/-10 \%$

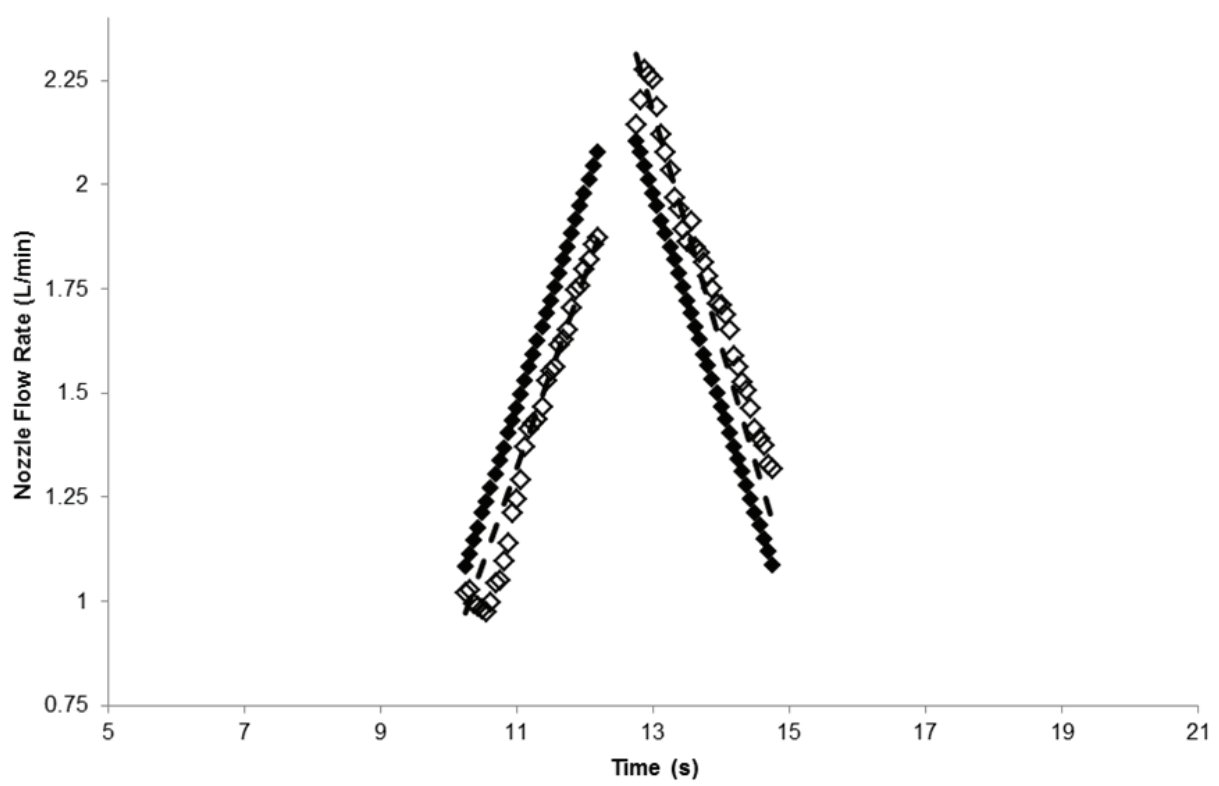

Figure 11. Ramp response of variable $K$ nozzle control at $138 \mathrm{kPa}$ and $0.2 \mathrm{~Hz}$. 


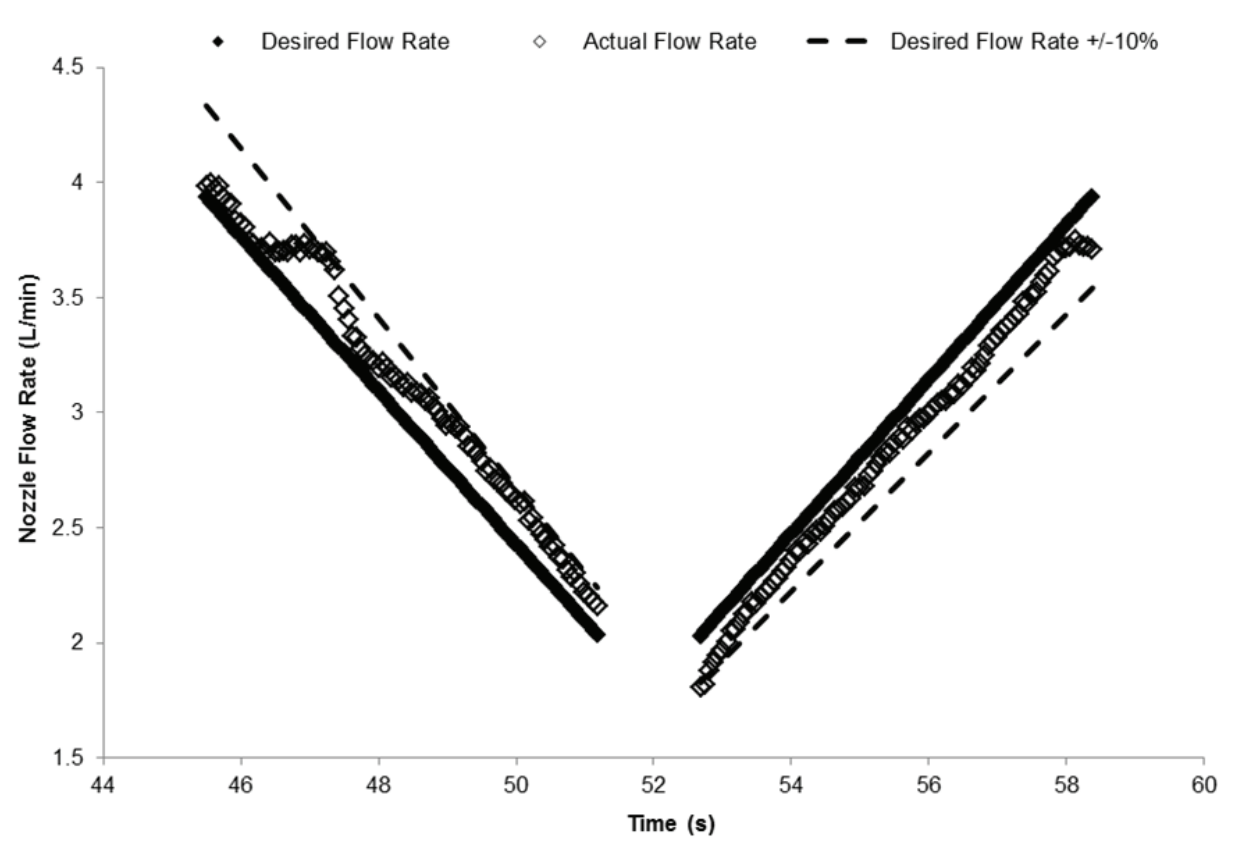

Figure 12. Ramp response of variable $K$ nozzle control at $345 \mathrm{kPa}$ and $0.07 \mathrm{~Hz}$.

$0.2 \mathrm{~Hz}$. In this situation, the magnitude of the error regularly exceeded $10 \%$ of $Q_{i n}$. In addition, the metering stem appeared to be extending and retracting as $Q_{\text {in }}$ changed direction from $Q_{\max }$ to $Q_{\min }$ and vice versa. Figure 12 shows the ramp response at $345 \mathrm{kPa}$ with $Q_{\text {in }}$ operating at $0.07 \mathrm{~Hz}$. Minor disturbances in the system response were visible at $47 \mathrm{~s}$; however, the nozzle was able to quickly respond to maintain appropriate flow rates (average absolute error was 4.9\%).

The sample data in these three figures illustrate the potential problem associated with solely observing lag time to characterize system response. Not only should lag time be evaluated, but the magnitude of the error must also be determined. When ignoring this problem, results such as those in figure 12 may be deemed acceptable when they may in fact be the cause of field application errors.

\section{CONCLUSIONS}

Laboratory tests were conducted to develop and evaluate an actively actuated (direct-operated electromechanical) variable-orifice nozzle for controlling carrier flow rate and preserving nozzle spray pattern and droplet size distribution for constant carrier pressures. The focus of this investigation was on development of automated controls and evaluating their response to step and ramp changes in control commands.

A variable gain $(K)$ digital control approach was developed for the modified VT nozzle. The system $K$ was continually calculated based on the system pressure, which ranged from 138 to $414 \mathrm{kPa}$. The control system was developed by analyzing the system step response. The goal was to achieve $t_{s}$ values less than $1.0 \mathrm{~s}, O S$ of less than $10 \%$ of $Q_{\max }$ (or $Q_{\text {min }}$ ), and average absolute $e_{s s}$ of less than $2 \%$. After several trials, the resulting control system achieved these objectives for full steps from $Q_{\max }$ to $Q_{\min }$ (and vice versa) at carrier pressures from 138 to $414 \mathrm{kPa}$. Ramp response analyses re- vealed the maximum $\Delta Q_{i n}\left(\mathrm{~mL} \mathrm{~s}^{-2}\right)$ of the nozzle control system. Tests were conducted at carrier pressures ranging from 138 to $414 \mathrm{kPa}$ and for $\Delta Q_{\text {in }}$ ranging from 0.02 to $0.2 \mathrm{~Hz}$. Operation was considered successful if the average absolute error was less than $5 \%$ and the average absolute error $+2 \sigma$ did not exceed $10 \%$ of $Q_{i n}$, thereby ensuring that the nozzle operated within specifications $95 \%$ of the time.

An additional goal was to maintain nozzle response lag times of less than $1.0 \mathrm{~s}$. Lag times were found to be less than $0.5 \mathrm{~s}( \pm 0.05 \mathrm{~s})$ over the carrier pressure range at input frequencies of up to $0.2 \mathrm{~Hz}$. Further, these results indicated that for each carrier pressure, a maximum $\Delta Q_{\text {in }}$ frequency of 0.07 $\mathrm{Hz}$ ensured that system errors were within the design requirements. Lag times at this frequency were less than $0.38 \mathrm{~s}$ for all carrier pressures tested. The range of $\Delta Q_{i n}$ achieved by the nozzle control system ranged from 2.97 to $6.39 \mathrm{~mL} \mathrm{~s}^{-2}$ for carrier pressures of 138 to $414 \mathrm{kPa}$, respectively. Thus, as operating pressure increased, the nozzle was capable of compensating for greater changes in the desired flow rate. An example scenario was chosen to illustrate that for a target rate of $93.5 \mathrm{~L} \mathrm{ha}^{-1}$ (51 cm nozzle spacing), the system could compensate for sprayer accelerations of up to $1.34 \mathrm{~m} \mathrm{~s}^{-2}$ at a carrier pressure of $414 \mathrm{kPa}$. These results were somewhat intuitive in that the metering stem travel was the same at all carrier pressures. Therefore, the constant speed of the actuator (i.e., metering stem) resulted in greater changes in nozzle flow rate at higher carrier pressures. While the turndown ratios $(\sim 2.4: 1)$ over the range of carrier pressures were essentially stable, flow rates increased with carrier pressure.

While the variable $K$ control system worked well for the current configuration of the VT nozzle (green cap), it should be noted that modifications to the system could result in the need to recalibrate the controller. For instance, the orifice size (four are currently available) may affect control system performance. Operating outside of the range of carrier pressures tested could adversely affect system 
response. This would be an unlikely occurrence, as the control system was developed for use in conjunction with a sprayer set up for constant carrier pressures. The range of carrier pressures tested in this study (138 to $414 \mathrm{kPa}$ ) covered the typical operating pressure range of the VT nozzle as reported by the manufacturer.

\section{ACKNOWLEDGEMENTS}

This material is based on work supported by the USDA Cooperative State Research, Education and Extension Service (CSREES) under Agreement No. 2009-0720-1146. Any opinions, findings, conclusions, or recommendations expressed in this publication are those of the authors and do not necessarily reflect the views of the USDA.

\section{REFERENCES}

Bui, Q. D. (1997). Design and development of a variable-flow fan nozzle using phase-partition air sampling for drift assessment. $\mathrm{PhD}$ diss. Knoxville, Tenn.: University of Tennessee, Department of Agricultural and Biosystems Engineering.

Bui, Q. D. (2005). VariTarget: A new nozzle with variable flow rate and droplet optimization. ASABE Paper No. 051125. St. Joseph, Mich.: ASABE.

Capstan. (2011). AIM Command. Topeka, Kans.: Capstan Ag Systems, Inc. Retrieved from www.capstanag.com/products/pinpoint.

Daggupati, N. P. (2007). Assessment of the VariTarget nozzle for variable-rate application of liquid crop protection products. MS thesis. Manhattan, Kans.: Kansas State University, Department of Biological and Agricultural Engineering.

Delavan. (2011). VariTarget variable flow rate nozzle. Mendota Heights, Minn.: Delavan AgSpray Products. Retrieved from www.delavanagspray.com/PDFs/VT-Flyer2007-Eng.pdf.

Dilawari, G., Taylor, R. K., Solie, J. B., \& Bennur, P. (2008). Nozzles for variable-rate fertilizer application. ASABE Paper No. 083732. St. Joseph, Mich.: ASABE.

Dorf, R. C., \& Bishop, R. H. (2008). Modern Control Systems (11th ed.). Upper Saddle Ridge, N.J.: Pearson Prentice Hall.

Giles, D. K. (1997). Independent control of liquid flow rate and spray droplet size from hydraulic atomizers. Atomization Sprays, 7(2), 161-181. http://dx.doi.org/10.1615/AtomizSpr.v7.i2.40.

Giles, D. K., \& Comino, J. A. (1990). Droplet size and spray pattern characteristics of an electronic flow controller for spray nozzles. J. Agric. Eng. Res., 47, 249-267. http://dx.doi.org/10.1016/0021-8634(90)80045-V.

Giles, D. K., Young, B. W., Alexander, P. R., \& French, H. M. (1995). Intermittent control of liquid flow from fan nozzles in concurrent air streams: Wind tunnel studies of droplet size effects. J. Agric. Eng. Res., 62(2), 77-84. http://dx.doi.org/10.1006/jaer.1995.1066.

GopalaPillai, S., Tian, L., \& Zheng, J. (1999). Evaluation of a flow control system for site-specific herbicide applications. Trans. ASAE, 42(4), 863-870. http://dx.doi.org/10.13031/2013.13265.

Han, S., Hendrickson, L. L., Ni, B., \& Zhang, Q. (2001). Modification and testing of a commercial sprayer with PWM solenoids for precision spraying. Appl. Eng. Agric., 17(5), 591594.

Han, Y. J., Bode, L. E., \& Hummel, J. W. (1986). Controlling chemical application rate with bypass spray nozzles. Trans. ASAE, 29(5), 1221-1227. http://dx.doi.org/10.13031/2013.30299.

Koo, Y. M., \& Kuhlman, D. K. (1993). Spray performance models of a designed swirl nozzle. Trans. ASAE, 36(3), 679-684. http://dx.doi.org/10.13031/2013.28385.

Kunavut, J., Schueller, J. K., \& Mason, P. A. C. (2000). Continuous control of a sprayer pinch valve. Trans. ASAE, 43(4), 829-837. http://dx.doi.org/10.13031/2013.2977.

Lebeau, F., El Bahir, L., Destain, M. F., Kinnaert, M., \& Hanus, R. (2004). Improvement of spray deposit homogeneity using a PWM spray controller to compensate horizontal boom speed variations. Computers Electronics Agric., 43(2), 149-161. http://dx.doi.org/10.1016/j.compag.2004.01.001.

Luck, J. D. (2012). Development of a variable-orifice spray nozzle with high-pressure chemical injection for improved pesticide efficacy. PhD diss. Lexington, Ky.: University of Kentucky, Department of Biosystems and Agricultural Engineering.

Luck, J. D., Sama, M. P., Pitla, S. K., \& Shearer, S. A. (2010). Pneumatic control of a variable-orifice nozzle. ASABE Paper No. 1009618. St. Joseph, Mich.: ASABE.

Luck, J. D., Sharda, A., Pitla, S. K., Fulton, J. P., \& Shearer, S. A. (2011). A case study concerning the effects of controller response and turning movements on application rate uniformity with a selfpropelled sprayer. Trans. ASABE, 54(2), 423-431. http://dx.doi.org/10.13031/2013.36445.

Luck, J. D., Pitla, S. K., Sama, MP., \& Shearer, S. A. (2015). Flow, spray pattern, and droplet spectra characteristics of an electronically actuated variable-orifice nozzle. Trans. ASABE, 58(2), 261-269. http://dx.doi.org/10.13031/trans.58.10798.

MicroDAQ. (2011). USB 1408FS user's guide. Norton, Mass.: Measurement Computing. Retrieved from www.microdaq.com/measurement_computing/documents/usb1408fs_usermanual.pdf.

Nise, N. S. (2008). Control Systems Engineering (5th ed.). Hoboken, N.J.: John Wiley and Sons.

Pierce, R. A., \& Ayers, P. D. (2001). Evaluation of deposition and application accuracy of a pulse width modulation variable-rate field sprayer. ASABE Paper No. 011077. St. Joseph, Mich.: ASABE.

Pontech. (1997). STP100 Stepper Motor Controller Board User's Manual. Rancho Cucamonga, Cal.: Pontech.

Porter, W. M., Rascon, J. A., Shi, Y., Taylor, R. K., \& Weckler, P. A. (2013). Laboratory evaluation of a turn compensation control system for a ground sprayer. Appl. Eng. Agric., 29(5), 655-662.

Reitz, S., Palyi, B., Ganzelmeier, H., \& Laszlo, A. (1997). Performance of electronic controls for field sprayers. J. Agric. Eng. Res., 68(4), 399-407. http://dx.doi.org/10.1006/jaer.1997.0217.

Rockwell, A. D., \& Ayers, P. D. (1996). A variable-rate, direct nozzle injection field sprayer. Appl. Eng. Agric., 12(5), 531-538. http://dx.doi.org/10.13031/2013.25680.

Shahemabadi, A. R., \& Moayed, M. J. (2008). Modification of a commercial PWM sprayer control system for precision farming application. Proc. Intl. Symp. Info. Tech. Piscataway, N.J.: IEEE. http://dx.doi.org/10.1109/itsim.2008.4631862.

Sudduth, K. A., Borgelt, S. C., \& Hou, J. (1995). Performance of a chemical injection sprayer system. Appl. Eng. Agric., 11(3), 343348. http://dx.doi.org/10.13031/2013.25747.

Vondricka, J., \& Schulze Lammers, P. (2009). Evaluation of a carrier control valve for a direct nozzle injection system. Biosys. Eng., 103(1), 43-48. http://dx.doi.org/10.1016/j.biosystemseng.2009.02.008.

Womac, A. R. (2001). Atomization characteristics of high-flow variable-orifice flooding nozzles. Trans. ASAE, 44(3), 463-471. http://dx.doi.org/10.13031/2013.6101.

Womac, A. R., \& Bui, Q. D. (2002). Design and tests of a variableflow fan nozzle. Trans. ASAE, 45(2), 287-295. http://dx.doi.org/10.13031/2013.8519.

Zaber. (2015). Linear actuator, NEMA size 14, $16 \mathrm{~mm}$ travel, $50 \mathrm{lb}$ force. Vancouver, British Columbia, Canada: Zaber Technologies, Inc. Retrieved from www.zaber.com/products/ product_detail.php?detail=NA14B16-T4\#tabs. 